\title{
The Present vs. the Specious Present
}

\author{
Jiri Benovsky
}

Published online: 22 November 2012

(C) Springer Science+Business Media Dordrecht 2012

\begin{abstract}
This article is concerned with the alleged incompatibility between presentism and specious present theories of temporal experience. According to presentism, the present time is instantaneous (or, near-instantaneous), while according to specious present theories, the specious present is temporally extended-therefore, it seems that there is no room in reality for the whole of a specious present, if presentism is true. It seems then that one of the two claims - presentism or the specious present theory-has to go. I shall argue that this kind of worries is mislead. Once we understand properly how our phenomenal experience as of passage and as of change, such as it is understood by specious present theorists, comes into being, the apparent phenomenologicometaphysical conflict will disappear. In short, the mistake here is to presuppose that there is a link between phenomenology and metaphysics stronger than it actually is. Presentism is a metaphysical theory about what exists. Specious presentism is a phenomenological theory about how things appear to us in experience. As we will see, the two claims are not in conflict, and are in fact entirely orthogonal.
\end{abstract}

This article is concerned with the alleged incompatibility between presentism and specious present theories of temporal experience. The worry that lies at the heart of this debate can be approached in a very general and somewhat simplistic way as follows :

i. The present, according to presentism, is instantaneous (or, near-instantaneous ${ }^{1}$ ). ii. The specious present is not instantaneous (however short, it encompasses a brief period of time).

\footnotetext{
${ }^{1}$ It seems required for the presentist to take the present time to be instantaneous, since otherwise the present would be temporally big enough to include successive events. But then, these successive events would all be present, and thus would all be simultaneous - which leads either to a contradiction, or to a completely confused notion of simultaneity. (Besides, even if the present were said to be of a short non-zero durationlike a 'chronon', a quantum of time, a discrete and indivisible "unit" of time of non-zero length - its length would still be much shorter than the length of a specious present, so our worry would arise here as well.) For good statements and defenses of presentism in general see for instance Merricks $(1994,1999)$ and Zimmerman (1998).

\section{J. Benovsky $(\square)$}

Department of Philosophy, University of Fribourg, Av. de l'Europe 20, 1700 Fribourg, Switzerland e-mail: jiri@benovsky.com

URL: www.jiribenovsky.org
} 
iii. Therefore, there is no room in reality for the whole of a specious present, if presentism is true. One of the two claims-presentism or the specious present theory-has to go.

Let us refer to this worry as "The Worry". Its 'argument' exhibits a tension between a metaphysical claim and a phenomenological one. On the one hand we have a metaphysical notion of the present time and on the other a notion of a phenomenal (specious) present. The Worry then claims that the two are incompatible.

In this article I shall argue that The Worry is wrong. The tension here is only apparent, there is no real problem, and the two claims - the metaphysical one and the phenomenological one - are in fact orthogonal. To see this, I will first examine in more detail what The Worry amounts to, and mention a possibly analogous worry in another (metaphysical) debate, before showing that the problem here is only due to a misunderstanding of what the specious present theorist means by "present" and that it can be easily avoided by appealing to recently developed philosophical insights about temporal experience coming from cognitive science.

Specious present theories come in various versions, as we shall see shortly, but they all stem from one central claim, famously put forward for instance by James (1890, p.629): "A succession of feelings, in and of itself, is not a feeling of succession. And since, to our successive feelings, a feeling of their own succession is added, that must be treated as an additional fact requiring its own special elucidation", who then adds that "the prototype of all conceived times is the specious present, the short duration of which we are immediately and incessantly sensible". Think of a skier going down the mountain. You can see her changing her position in a continuous and smooth way, you can see her moving. You do not have a succession of different experiences of different spatio-temporal positions of the skier, rather you have one continuous experience of her movement. To account for this type of experiences, specious present theories claim that we need a notion of a non-zero temporal duration which, in our experience, our mind embraces 'at once': the specious present. The length of the duration of a specious present is often not very clearly specified, varying in the literature from milliseconds to a full minute, but for the purposes of The Worry this does not really matter, since in any case any such interval of time will be much longer than the length of a presentist's present (especially if the latter is instantaneous). Among friends of the notion of a specious present one can cite Kant (1781), James (1890), Husserl (1964), and Broad (1923), and more recently Foster (1982, 1992), Dainton (2000, 2003), Hoerl (2009), and Phillips (2011), but these philosophers do not form a unified band, rather they fight tooth and nail about how one should understand and spell out this notion crucial to the understanding of our temporal experience. In this article, I shall focus on two main rivals : extensionalism and retentionalism.

The extensionalist view, recently largely defended by Dainton (2000, 2003, 2008, 2010), has the virtue of simplicity: according to this view, the specious present is temporally extended exactly as events in the world are. The movement of the skier down the mountain extends in time, and so does our experience of it —our experience is 
such that it is composed of very short but temporally extended overlapping experiences featuring temporally extended and temporally ordered content, where this content is given to us 'as present', or 'as occurring now'. Thus, one understands here the notion of the specious present in a very straightforward way, namely that our experiences are temporally extended and that their content is both temporally ordered and unified into a single experiential episode which appears to us as present. The content of a specious present thus appears to us both as having temporal structure-successive temporal parts - and as present (if this sounds contradictory to you, wait for section 6 below).

The retentionalist's Husserlian idea is quite different. According to retentionalism, the specious present is not temporally extended, it is instantaneous. This is where retentionalists and extensionalists disagree. But what they agree on is that the specious present has temporally extended content. Under retentionalism, this is so because the instantaneous experience - say of the skier at some point of her descent - has as components of its content states of the skier at some previous instants as well, and all of these are then given to us in the experience as present. The previous states of the skier are not understood here as being temporal parts of the specious present in the sense of the extensionalist - rather, they are retentions. Retentions are not memories in the sense of rememberings, rather they are parts of the content of a specious present exhibiting more or less "presentedness" (this is Broad's term), which provides a temporal order among them, where presentedness is the phenomenal quality of appearing to us as present. Thus all of the parts of a specious present appear to us as present, but some of them appear to us, so to speak, as more present than others.

Now we can start to better understand what The Worry is all about. The primary target of The Worry is the combination of presentism and the extensionalist view, as Dainton very clearly argues:

If reality is confined to a momentary present in the way Presentists maintain, then it is difficult to see how any form of the Extensional approach can be true. Our immediate experience cannot extend through time if time itself has no extension; if earlier and later stream-phases are experienced together, in the way Extensional models require, then it seems very plausible to suppose that these phases must both exist. (Or to put it another way: an experience which no longer figures in the sum total of reality is not in a position to be part of the same unified state of consciousness as an experience which does so figure, any more than a non-existent brick can help hold up a wall.

(Dainton $(2010,7.2))$

Since Extensional specious presents comprise earlier and later phases that are experienced together, in a single unified (albeit extended) state of consciousness, it may well be that Extensional models are incompatible with the Presentist conception of time, according to which only what is present is real. For two phenomenal contents $\mathrm{C} 1$ and $\mathrm{C} 2$ be experienced together, to be diachronically co-conscious, both $\mathrm{C} 1$ and $\mathrm{C} 2$ must surely both exist. But if Presentism were true, when $\mathrm{C} 1$ is present $\mathrm{C} 2$ would be non-existent, and when $\mathrm{C} 2$ is present C1 would be non-existent. (Dainton $(2010,5.5)$ ) 
At a first sight, retentionalism seems to be immune to this Worry, since as we have seen, according to this view the specious present is instantaneous-so, there is room in reality for the whole of a retentionalist's specious present. But there is a similar worry in the neighbourhood. The retentionalist's specious present is conceived of as a relational affair: the present specious present bears relations (of retention) to other, past, specious presents. This is how it is said to have a content with temporal extent. But then, if presentism is true, we find ourselves in a situation where a present (i.e. existing) entity, namely the present specious present, stands in a relation to other nonpresent (i.e. non-existing) entities, namely the previous (now past) specious presents. The extensionalist's sin seems to be to claim that there are entities that have parts that do not exist, and similarly the retentionalist seems to have to endorse here the claim that an entity can stand in a relation (of retention) to entities that do not exist. This might be argued to be as problematic as having past parts that don't exist, since it seems strange, to say the least, to claim that there is a relation with two relata where one of the relata exists while the other does not.

This version of The Worry sounds probably familiar to those who are involved in the debate about persistence through time of ordinary material objects, so allow me a short detour to illustrate our Worry by mentioning this structurally analogous issue.

The issue I have in mind here concerns the incompatibility between presentism and perdurantism. (I discuss it in detail in Blinded for Review), here let me only briefly point to it. Perdurantism comes in two mains versions: the worm view and the stage view. Let us shortly examine them in turn.

According to the worm view, ordinary material objects, like tables or skiers, persist through time by being temporally extended, that is, by having temporal parts at different times. But then, since such objects are wholes which are temporally bigger than an instant (much bigger, usually), they are temporally too big to be able to exist at one instant, thus they cannot entirely exist at one time, and in particular they cannot entirely exist at the present time - only a very small part of them can. But then, if presentism is true and only what exists at the present time exists, these objects are strangely such that they never entirely exist - only a part of them ever does. Of course, following presentism, one could say that the non-existing parts of these objects once existed, but in what sense could they then be said to be parts of any presently existing object? The very plausible principle involved here was put forward by Merricks (1995, p.524): "an object cannot have another object as a part if that other object does not exist". Indeed, it seems entirely puzzling to claim that there is an ontological glue that would allow for mereological composition to take place between an entity that exists and nothing. Thus, the combination of the worm view with presentism fails.

The stage view differs from the worm view in an important sense: it claims ordinary material objects, like tables or skiers, to be instantaneous entities — "stages". These entities do not, so to speak, persist through time themselves, rather they are said to persist through time by having temporal counterparts at other times - that is, by bearing a counterpart relation (which is typically a relation of causality, similarity, 
and spatio-temporally connectedness) to other entities existing at other times. Thus, if presentism is true, the stage view does not create any special problem about how an object can exist entirely at the present time, since all objects are instantaneous and thus temporally small enough to fit in the realm of reality. But a neighbouring problem, easy to guess now, arises. Indeed, under this view, ordinary material objects have counterparts at other (past) times, and so they stand in a counterpart relation with things that do not exist. Take Mary who is skiing down a mountain and who undergoes qualitative change: she is first bent, say at $t_{1}$ when she starts a turn, and then straight at $t_{2}$ when she is finishing her turn. Say that $t_{2}$ is the present time. According to the stage view, Mary at $t_{1}$ and Mary at $t_{2}$ are two qualitatively and numerically different entities, which are counterpart-related. But how could they be? How could a non-existing entity (Mary at $t_{1}$ ) bear any degree of similarity and have any other (spatio-temporal and causal) relations to an existing flesh-and-blood person (Mary at $\mathrm{t}_{2}$ - the present time)? Nothing non-existing can be sufficiently similar and related to anything existing so as to be counterpart-related with it. In general, the counterpart relation will never hold between the two numerically distinct entities simply because there never is a time when both exist - the two relata of the counterpart relation just cannot both exist. Thus, the combination of presentism and the stage view also fails, since even if it seems to answer the objection about having parts that don't exist, it immediately gives rise to a different but parallel objection about counterparts that don't exist. ${ }^{2}$

The structural analogy between worries concerning presentist perdurantism and The Worry helps us to get a better grip on what The Worry amounts to. The worm view and extensionalism seem committed to the having of parts that do not exist, while the stage view and retentionalism appear to be obliged to appeal to relations that hold between an existing entity and nothing. Until now then, if anything good comes out of these considerations, it is the good news for the extensionalist that she is not the only one having compatibility issues with presentism: The Worry, in a different form, applies to retentionalism as well.

One possible way out of trouble for specious present theorists is then to argue that what The Worry shows is that one should reject presentism. This is Dainton's own stance: "Extensional theorists will not be overly worried by this consequence, which they will construe as a reason for rejecting the Presentist conception of time." (Dainton $(2010,5.5)$ ) and "[...] although there has been a renewed interest in it, Presentism remains a highly controversial view of time, one which many regard as untenable" (Dainton (manuscript, section 2)). Indeed, presentism has troubles of its own, some of which are often regarded as conclusively lethal, like its incompatibility with special relativity, as well as other problems such as the difficulties it has to

\footnotetext{
${ }^{2}$ Defenders of the Stage View, who provide a general account of how an object (a stage) can have its properties in virtue of standing in relations to other objects (stages), include Sider (2001, p.188-) and Varzi (2003).
} 
provide truth-makers for propositions about the past (see for instance Sider (2001, chapter 2) for a good discussion).

But there is something itchy about such a dialectical move, for more often than not considerations coming from the phenomenology of our experience of time are taken to motivate a presentist (in general, any A-theoretic) conception of time. It is indeed often taken to be an important point in favour of presentism that we experience time as passing and that presentism is the only view that can account for genuine temporal passage in the world, precisely by making the present to be ontologically special. At least from the presentists' point of view, it would then be odd (and unwelcome) to see one of the main line of argument in favour of their view to turn against it.

Thus, if one could show that The Worry is misguided and that there is no threat arising from the combination of presentism and specious present theories, it would not only be good news for extensionalists and retentionalists, who would not have to burden themselves with a heavily metaphysically loaded claim about the falsity of presentism, but also for presentists themselves. This will be the job of the next two sections.

\section{5}

The intuitive idea behind The Worry does of course has some bite: if $x$ is said to be extended in time by having temporal parts, then if these parts do not exist, $x$ cannot be extended in time after all (and similarly for the relational versions of The Worry as we saw above). Perhaps the first step towards a way out of trouble is here is to recognize that the two different debates, namely the debate about specious present theories and presentism, and the debate about perdurantism and presentism, are not analogous in the right sense. Granted, the views involved and the worries that arise in both debates are structurally analogous, as we have seen in section 3 above, but very importantly the latter debate is concerned with a claim of incompatibility between two metaphysical theories, while the former argues for an incompatibility between a metaphysical theory and a phenomenological one. This makes an important difference. As we shall see below, once we understand properly how our phenomenal experience as of passage and as of change comes into being, the apparent phenomenologico-metaphysical conflict will disappear. In short, The Worry's mistake is to suppose that there is a link between phenomenology and metaphysics stronger than it actually is.

When it comes to temporal experience, our perceptual capacities are limited in an interesting way. Let us focus on our perception of movement, since it is often via perception of movement that we perceive change and temporal passage. When perceiving a movement that is too slow-say, the movement of the hour hand on mechanical clock - we do not perceive it as moving, we can only see that it has moved when we compare its position at some time and at a later time. Similarly when we perceive a movement that is too fast-say, a dot on a computer screen moving quickly along a circular path -we do not perceive it as moving either, rather we perceive a static non-moving circle. The reason is that our perceptual system has lower and upper limits beyond which we are not capable of perceiving movement as movement, and it is only in cases when a movement takes place at an appropriate speed, like the one of Mary skiing down the mountain, that we have an experience of 
her moving, since in this case her speed remains well between the lower and upper limits of our perceptual system's recognitional capacities, and thus it is interpreted as moving. Our experience as of change, movement and succession in this and similar cases thus comes from the fact that the inputs our perceptual system gets from the world 'hit' it at an appropriate speed.

Taking a further step, L. A. Paul (2010) provides a sophisticated account of our temporal experience based on considerations about how brains of conscious beings experience and interpret cognitive inputs from series of static events. She bases her observations on the phenomenon of "apparent motion" where the perceiving subject has an experience as of movement and as of change while there is none, for instance, when a dot on a computer screen is shown on the left side of the screen and then quickly enough (but not too quickly) on the right side of the screen, we have the illusory experience that the dot moves from left to right, when in fact there are two different dots shown separately - in reality, nothing has moved. Because of the limits of our perceptual capacities, we thus have the illusion of movement where there is none, a phenomenon which is exploited in the film industry where apparent motion in a movie is generated by a series of static images succeeding each other at an appropriate speed (between 24 and 30 images per second, usually). This 'illusion' has nothing to do with our knowledge or ignorance of whether there is genuine movement in the world or not, since the appearance of movement persists even when we know that it is illusory (both in the case of the two dots and the case of cinema). Now, as Paul (2010, p. 16) argues, in order to explain these phenomena of apparent motion, we have to recognize that it is prior to any conscious experience that our perceptual system, on a psycho-neurological but not on a phenomenal level, interprets the successive stimuli in such a way as to produce a phenomenal experience of movement. This claim is no stranger to specious present theorists, as for instance Dainton (2008, section 5) puts it: "[our brains] try to work out a single, coherent version of events on the basis of the fragmentary and (at times) conflicting data available to them. Only this 'final draft', as it were, reaches consciousness".

The claim, backed up by research coming from cognitive science and experimental psychology (see Paul (2010)), consists then in two different stages, one of them being precognitive and non-phenomenal where our brain via our perceptual system gets inputs from the world and interprets them, and the other that is phenomenally accessible to us where we (can) have an experience as of movement.

If this is correct, and if one presupposes presentism, then when we have a conscious experience (say, as of movement) no part of this experience is such that it represents something existing, of course. There is a trivial sense in which this is true, and a less trivial and more interesting one. Trivially, since the speed of light is finite and since it takes then some time for any information from the world to reach us and for our optic nerve to pass the information on, etc., anything we are consciously aware of is, in a presentist world, long gone from the realm of reality. But this trivial truth is not what The Worry is about. Indeed, The Worry is not so much interested in the things that caused an experience, which are past (and thus, according to presentism, non-existing), but in the experience itself.

What the phenomenological claim is about is the temporal extent of the content of an experience, and what we want to understand here, and what specious present theorists provide an answer to in their own way, is how our experience is such that it 
is both an experience with temporally extended and temporally ordered content and an experience whose content is given to us 'at once' or 'together' or, as specious present theorists themselves often say, 'as present'. Retentionalism answers the question by appealing to relations of retention, while extensionalism answers it by claiming that the specious present's phenomenal structure is such that is has phenomenal temporal parts.

But then, given the discussion above, we can understand here easily how we can have an experience with a temporally extended content even under presentism: trivially, we always only have experiences of entities which are past and nonexisting, but an experience itself is an existing present instantaneous mental entity (as all entities are, if presentism is true-instantaneous, present, and existing). This does not prevent the experience from having a temporally extended representational phenomenal content-say, along with the extensionalist, by having phenomenal temporal parts. This, I take it, is what really counts for the extensionalist - or, at least, this is what should count for her. Extensionalism (and similarly for retentionalism as well) is a phenomenological claim about how things appear to us in experience; it is not - or at least it better not be-an ontological claim about the experience qua mental entity. Thanks to the understanding we saw above of how such experiences come into being, after having been processed non-phenomenally and unconsciously by our brain, we now have a good understanding about how we can have an instantaneous experience with a temporally extended content-i.e. a phenomenal appearance which is the end result of complex processing which takes some time and processes several successive and metaphysically speaking non-simultaneous 'inputs' our perceptual system gets from the world. Under extensionalism, as we saw above, this is then spelled out in terms of phenomenal temporal parts (as opposed to 'metaphysical' temporal parts).

In short, the brain takes the time to accumulate successive (metaphysically) nonsimultaneous stimuli, and uses them to produce a unique experience with temporally extended content. The non-simultaneous inputs of course never co-exist if presentism is true, but there is no problem there. The brain simply keeps a record of them and processes this information in order to produce an experience whose content is a result of these different stimuli. Extensionalism qua phenomenological claim is an analysis of the phenomenal content of our temporal experience, and it tells us that it has phenomenal temporal parts. This does not imply in any sense that the mental entity that is the experience is itself, qua metaphysical entity, temporally extended —or at least, my suggestion is that there is no pressure on the extensionalist to commit to such a metaphysically loaded claim. (And this is where The Worry is relevantly not analogous to the debate about presentist perdurantism.) Specious present theories are thus fully neutral with respect to the eternalism vs. presentism controversy, since they are perfectly compatible with both and since, most importantly, their claims are of a phenomenological nature. The notion of temporal extension in the extensionalists' view is a notion of phenomenal temporal extension, and similarly for the retentionalist who instead of a notion of 'phenomenal temporal parthood' appeals to a notion of retention.

To see this even more clearly let us consider two objections that are sometimes raised against extensionalism and against specious present theories in general. 
Kelly (2005, section 5) raises an interesting objection to extensionalism: "According to this theory of the nature of perceptual experience, we are in direct perceptual contact not only with what is now occurring but also with what has recently occurred and indeed with what is about to occur as well. [...] A third challenge for the Specious Present Theory is to explain how I can be directly aware of the near future. [...] It is odd enough to think that we could be directly aware of something that was occurring but no longer is. But it is odder still to think that we can be directly aware of something that has not yet occurred."

To make this objection interesting, one must suppose that it is not trivially wrongheaded in the sense that it ignores the fact that we always only perceive the past because of the finite speed of light and the time it takes our perceptual system to pass on information it gets from the world. There is a trivially true sense in which we only experience the past, but this is not what the objection is about-otherwise it would be just wrong. The objection, directed against extensionalism, is more subtle. According to extensionalism, a specious present is temporally extended but all of it is phenomenally given to us 'at once' or 'as present'. Whenever we have a specious present experience, we experience all of its temporal parts together. But then, suppose that you hear three notes in a rapid succession within a single specious present- they are given to you as occurring both successively and 'as present'. But metaphysically speaking, in the world, these three notes occur at different times (say, $t_{1}, t_{2}, t_{3}$ ). The objection then asks: suppose that now is the time $t_{1}$, what do I have an experience of ? Since I have an experience of the specious present, I should by definition be aware of the whole of the content of this specious present, but this seems wrong since the second and third note occur at future times $\left(t_{2}\right.$ and $\left.t_{3}\right)$.

It is easy to see how the extensionalist can respond to such a worry, by appealing to the account we have seen above. Indeed, the extensionalist will not only accept the trivial truth that we always only experience the past, but furthermore she can accept that there is some temporal discrepancy between the objective time at which things occur in the world and the objective time at which we become phenomenally/consciously aware of them, due to the fact that our brain takes some time to record and store external stimuli from the world before producing a conscious and phenomenally accessible experience - and if that's the extensionalist view one has in mind, situations like those described by Kelly will simply never occur. The very general recipe which allows the extensionalist to face Kelly's concern, and which is what I want to insist upon in the light of what I said in the previous section, is that one must strictly dissociate the notion of phenomenal temporal parts and the notion of 'metaphysical' temporal parts - these are two very different notions, that one must not treat alike. To see this even better, let us consider a final standard objection to specious present theories.

A standard objection to specious present theories (both extensionalist and retentionalist) arises from the very notion of a specious present. Indeed, as we already saw, specious present theorists claim that we have an experience such that its content is temporally ordered as a succession but we experience all of it as present. At a first glance, there seems to be something contradictory about such a claim. Indeed, it would be a contradictory claim, if it meant to say that the content of a specious present is both temporally ordered and has successive temporal parts and present, where 
"present" would be taken to have a temporal meaning. In short, the whole of the content of a specious present would then be said to be simultaneous (present) and non-simultaneous (temporally ordered).

But of course, specious present theorists are not making any such contradictory claim. In the mouth of a specious present theorist "present" does not mean "simultaneous" in the temporal sense, and neither it means "non-simultaneous" for that matter-it is a notion of phenomenal presence, not of metaphysical simultaneity, presence, or coexistence. What the specious present theorists wants to talk about is not how things are or are not ordered in the world and which of them are simultaneous and which are not. Specious present theorists wants to point to the phenomenal fact that in cases of experiences like the one of Mary skiing down the mountain our experience is such that it has a temporally ordered content which we embrace, in our experience, at once, together, or as specious present theorists indeed often say, as present-but "present" is not given a temporal meaning here, it is a purely phenomenal non-metaphysical notion. No contradiction arises then from the claim that we have experiences with temporally ordered content which is given to us 'together'. (Of course, the specious present theorist then owes us an explanation of what 'together' means.)

Again, the initial tension was only an apparent one, due to the ambiguity of the term "present". If the term were taken in a temporal metaphysical sense, there would indeed be a serious threat of a contradiction, but since it is a non-temporal phenomenological term (which does not mean "simultaneous" in the metaphysical sense) the threat in fact does not arise.

The misunderstanding that plays a crucial role in the two objections I shortly discussed in this section and the way specious present theorists reply to them is symptomatic of what my overall claim in this article is about. The Worry is not a real one. It only appears to exhibit a serious problem because it does not distinguish clearly enough about which claims are metaphysical and which are phenomenological. Presentism is a metaphysical theory about what exists. Specious presentism is a phenomenological theory about how things appear to us in experience. As we saw, the two claims are not in conflict, and are in fact entirely orthogonal ${ }^{3,4}$.

\footnotetext{
${ }^{3}$ The way I suggest extensionalists should go, namely the claim that extensionalism is a purely phenomenological thesis (about phenomenal temporal parts) and not a metaphysical thesis (about metaphysical temporal parts), might be seen as a way for the extensionalist to be closer to retentionalism than what we might have thought. What I argued for in this article is that this is a way the extensionalist should go, otherwise all sorts of objections, like The Worry and the two objections from section 6, would indeed seriously arise against extensionalism. What these objections show, however, is not that extensionalism is false; rather, they show that a certain understanding of extensionalism - namely the claim that extensionalism is partly a metaphysical claim - is wrong. One should understand extensionalism as being a purely phenomenological claim, and this is one of the main claims of my article. Furthermore, 'being closer' to retentionalism is not a bad thing for extensionalism. After all, both views are of the same kind: they are both Specious Present theories, so it is no surprise that they are close to each other-they are more like quarrelling brothers than like enemies at war. Important differences still remain: extensionalism appeals to a notion of phenomenal temporal parthood, while retentionalism does not. As a consequence, the way the two views analyze the structure of the specious present is different. Both views owe us here an explanation: in the extensionalist's case it is an explanation of what phenomenal temporal parthood and 'phenomenal togetherness' are, while in the retentionalist's case there is a need for an explanation of the nature of retentions.

${ }^{4}$ I am very grateful to Barry Dainton, Thomas Jacobi, Baptiste Le Bihan, L.A. Paul, and Gianfranco Soldati for discussions, comments, and objections that significantly helped me to improve this paper.
} 


\section{References}

Broad, C.D. 1923. Scientific thought. New York: Harcourt, Brace and Co.

Dainton, B. 2000. Stream of consciousness. London: Routledge.

Dainton, B. 2003. Time in experience: reply to Gallagher. Psyche 9(10).

Dainton, B. 2008. Sensing change. Philosophical Issues 18, Interdisciplinary Core Philosophy.

Dainton, B. 2010. Temporal consciousness. In Stanford encyclopaedia of philosophy, online.

Dainton, B. manuscript. The Phenomenal Continuum. Accessible online at http://barrydainton.com/papers.

Foster, J. 1982. The case for idealism. London: Routledge and Kegan Paul.

Foster, J. 1992. The immaterial self. London: Routledge.

Hoerl, C. 2009. Time and tense in perceptual experience. Philosophers' Imprint 9, $\mathrm{n}^{\circ} 12$.

Husserl, E. 1964. The phenomenology of internal time-consciousness. In ed. M. Heidegger (trans: Churchill, J.S.). Bloomington: Indiana University Press.

James, W. 1890. The principles of psychology. New York: H. Holt and company.

Kant, I. 1781. Critique of pure reason. (trans: Guyer, Paul, and Allen Wood), Cambridge: Cambridge University Press, 1998. Originally published in 1781/1787.

Kelly, S. 2005. The puzzle of temporal experience. In Cognition and the brain: The philosophy and neuroscience movement, ed. Andrew Brook. Cambridge: Cambridge University Press.

Merricks, T. 1994. Endurance and indiscernibility. The Journal of Philosophy 91: 165-184.

Merricks, T. 1995. On the incompatibility of enduring and perduring entities. Mind 104: 523-531.

Merricks, T. 1999. Persistence, parts and presentism. Noûs 33: 421-438.

Paul, L.A. 2010. Temporal experience. Journal of Philosophy 107(7): 333-359.

Phillips, I. 2011. Indiscriminability and experience of change. The Philosophical Quarterly 61: 808-827.

Sider, T. 2001. Four-dimensionalism. Oxford: Oxford University Press.

Varzi, A. 2003. Naming the stages. Dialectica 57: 387-412.

Zimmerman, D. 1998. Temporary intrinsics and presentism. In Metaphysics: The big questions, ed. Van Inwagen and Zimmerman. Malden: Blackwell. 